measured from the stationary fix. The longitude of the stationary fix can be found from this meridian angle and the GHA of the second body.

Once the stationary fix is known, the running fix can be found graphically. Obtaining a two-body stationary or running fix in this way requires somewhat more arithmetic than is needed for a running fix using DR positions. The difference is the second step, involving the solution of a time-sight navigational triangle. Tables for solving time-sights are hard to find nowadays, and it would usually be necessary to grind through an oldfashioned calculation with five-figure logarithms. The purpose of the last paragraph is to point out that it can be done if the need arises.

Example. On June 3,1989 , a small-boat navigator took two sets of five sights of the Sun, averaging each set in order to obtain a running fix. Course and distance made good between the two sets of sights were $049^{\circ}, 17.5$ miles. After averaging, data for sight reduction were as shown in Table $I$.

Chiesa and Chiesa's procedure gives, using their notation: $D=40^{\circ} 244^{\prime}, R=$ $81^{\circ}$ I $8 \cdot 6^{\prime}, \alpha=42^{\circ} 33^{\circ} 3^{\prime}, R_{1}=3^{\circ} 45^{\circ} 3^{\prime}, R_{2}=123^{\circ} 5^{\circ} 9^{\prime}$. The two possible stationary fixes are (1) $3^{\circ} 19^{\circ} 3^{\prime} \mathrm{N}, 73^{\circ} 41^{\circ} 7^{\prime} \mathrm{W}$; (2) $9^{\circ} 24^{\circ} 6^{\prime} \mathrm{N}, 72^{\circ} 43^{\circ} 3^{\prime} \mathrm{W}$. Comparison with the DR position $\left(3^{\circ} 30^{\prime} \mathrm{N}, 73^{\circ} 43^{\prime} \mathrm{W}\right)$ establishes the first stationary fix as the correct one. The azimuths calculated for this position are $Z_{1}=117.2^{\circ}, Z_{2}=227.5^{\circ}$. From Step (7), $d=6 \cdot 9^{\prime}$. From step (8), $A=27 \cdot 2^{\circ}$ and $A^{*}=207^{\circ} 2^{\circ}$; Step (9) then leads to $B=137.5^{\circ}$. Finally, since $A \leqslant C \leqslant A^{*}$, Step ( 10 ) gives $\phi^{\prime}=3^{\circ} 14^{\circ} 2^{\prime} \mathrm{N}, \lambda^{\prime}=73^{\circ} 35^{\circ} 7^{\prime} \mathrm{W}$. It may be verified that this position satisfies equations (4) and (5) of Williams ${ }^{2}$ with residual errors whose magnitude is $0^{\prime} \mathbf{I}^{\prime}$ or less.

Figure $I$ is a plot of this running fix. For comparison, the 1801 position computed from the original ten sights by the nonlinear least-squares algorithm of Severance ${ }^{7}$ was $38^{\circ} 13^{\circ} 8^{\prime} \mathrm{N}, 73^{\circ} 355^{\prime} \mathrm{W}$. Also for comparison, calculation of the stationary fix using Ageton's method and the time-sight formula of Rust ${ }^{8}$ gave $90^{\circ}-D=49^{\circ} 35^{\circ} 5^{\prime}, R=$ $81^{\circ}$ I $9^{\circ} 0^{\prime}, \alpha=42^{\circ} 33^{\circ} 5^{\prime}, \phi=38^{\circ} 19^{\circ} 0^{\prime} \mathrm{N}, t=17^{\circ} \circ 8 \cdot 5^{\prime}$, and $\lambda=73^{\circ} 41^{\circ} 5^{\prime} \mathrm{W}$.

\title{
REFERENCES
}

${ }^{1}$ Chiesa, A. and Chiesa, R. (1990). A mathematical method of obtaining an astronomical vessel position. This Journal, 43, 125.

2 Williams, R. (1990). Computation of an astronomical running fix. This Journal, 43, 444.

${ }^{3}$ Metcalf, T. R. (199I). Advancing celestial circles of position. Navigation, 38, 285.

4 Brown, C. (1991). Astro without azimuth. This Journal, 44, 428.

${ }^{5}$ Pepperday, M. (1992). The 'two-body fix' at sea. This Journal, 45, 138.

6 Spencer, B. (1990). Astronomical fixes without an assumed position. This Journal, 43, 449.

7 Severance, R. W. (1989). Overdetermined celestial fix by iteration. Navigation, 36, 373 .

${ }^{8}$ Bowditch, N. (1977). American Practical Navigator (chapter XXI). US Defence Mapping Agency.

KEY WORD

1. Astro.

\section{Shortest Spheroidal Distance}

\section{Tim Zukas}

What is the shortest distance on the terrestrial spheroid between two widely separated points, given their latitudes and longitudes (and the dimensions of the chosen spheroid)? 
Several articles in this Journal have discussed this question without settling it. The results of Williams and Phythian ${ }^{1}$ can differ from those of Lambert ${ }^{2}$ (as given by Hiraiwa $^{3}$ ) by $2 \mathrm{~km}$. None of the articles mentioned the formulas given by Sodano, ${ }^{4}$ Rainsford, ${ }^{5}$ and Vincenty. ${ }^{6}$ The latter two claim accuracy to about a millimetre over distances of $19000+\mathrm{km}$. Take one example from Hiraiwa: two points, both at $60^{\circ}$ geodetic latitude, are separated by $100^{\circ}$ of longitude. Hiraiwa uses Lambert's formula to get a distance on the Bessel spheroid of 2709.27 geographical miles; Williams and Phythian say $2708 \cdot 12$. Lambert's alternative formula, using reduced latitudes, gives $2709 \cdot 2861$. Sodano's standard formula gives $2709^{\cdot 286} 26$; his higher-precision formula and Rainsford's and Vincenty's formulas all give $2709^{\cdot 286} 35^{6}$.

The special case of equator-to-equator arcs (discussed by Williams and $\mathrm{Phythian}^{7}$ ) greatly simplifies Rainsford's and Vincenty's formulas for the quantity $(\lambda-L)$, enabling us quickly to find the half-period of a geodesic with any given vertex latitude. Any of the formulas will then calculate the length of the equator-to-vertex arc, which we then double. It turns out that the geodesic (on the Bessel spheroid) with vertex at $45^{\circ}$ geocentric latitude measures $1077^{\circ} .96$ geographical miles and $179^{\circ} 34^{\circ} 5^{26^{\prime}}$ of longitude between each crossing of the equator.

\title{
REFERENCES
}

1 Williams, R. and Phythian, J. E. (1989). Navigating along geodesic paths on the surface of a spheroid. This Journal, 42, 129.

${ }_{2}^{2}$ Lambert, W. D. (1942). The distance between two widely separated points on the surface of the Earth. Journal of the Washington Academy of Sciences, 32, 125.

${ }^{3}$ Hiraiwa, T. (1987). Proposal on the modification of sailing calculations. This Journal, $4^{\circ}$, 138.

${ }^{4}$ Sodano, E. M. (1965). General non-iterative solution of the inverse and direct geodetic problems. Bulletin Geodesique, 75.

${ }^{5}$ Rainsford, H. F. (1955). Long geodesics on the ellipsoid. Bulletin Geodesique, 37, 12.

${ }^{6}$ Vincenty, T. (1975, 1976). Direct and inverse solutions of geodesics on the ellipsoid with application of nested equations. Survey Review, 22, 176, 88; additional formulas, 23, 180, 294.

7 Williams, R. and Phythian, J. E. (1992). The shortest distance between two nearly antipodean points on the surface of a spheroid. This Journal, 45, I 14.

See also:

Bowring, B. R. (1983). The geodesic inverse problem. Bulletin Geodesique, 57, 109 (Correction, $58,543)$.

Meade, B. K. (1981). Comments on formulas for the solution of direct and inverse problems on reference ellipsoids using pocket calculators. Surveying and Mapping, 4I, I (March), 35.

KEY WORD

I. Geodesy.

\section{The Adventures of Leonard}

\author{
J. B. Parker
}

This article, though light-hearted, has a serious purpose, which is to attempt to act as an aperitif to the many distinguished articles about the Kalman filter, some of which are referred to in the text. Such articles have appeared both in the Journal and in Navigation News. 